\title{
Clinical Significance of Extended-spectrum $\beta$-lactamase- producing Bacteria in First Pediatric Febrile Urinary Tract Infections and Differences between Age Groups
}

\author{
Sun Yeong Park, M.D. \\ Ji Hong Kim, M.D. \\ Department of Pediatrics, Yonsei \\ University College of Medicine, Seoul, \\ Korea
}

Corresponding author: Ji Hong Kim, M.D. Department of Pediatrics, Yonsei University College of Medicine, Gangnam Severance Hospital, 211 Eonju-ro, Gangnam-gu, Seoul 06273, Korea

Tel: +82-2-2019-3352

Fax:+82-2-2019-4881

E-mail:KKKJHD@yuhs.ac

Received: 7 October 2017 Revised: 7 October 2017

Accepted: 10 October 2017
This is an open-access article distributed under the terms of the Creative Commons Attribution Non-Commercial License (http:// creativecommons.org/licenses/by-nc/4.0/) which permits unrestricted non-commercial use, distribution, and reproduction in any medium, provided the original work is properly cited.
Purpose: Extended-spectrum $\beta$-lactamase-producing bacteria-induced urinary tract infections are increasing and require more potent antibiotics such as carbapenems. We evaluated the clinical significance of extended-spectrum $\beta$-lactamase urinary tract infection in children younger than 5 years to select proper antibiotics and determine prognostic factors. Differences were compared between age groups. Methods: We retrospectively studied 288 patients with their first febrile urinary tract infection when they were younger than 5 years. Patients were divided into extended-spectrum $\beta$-lactamase-positive and extended-spectrum $\beta$-lactamasenegative urinary tract infection groups. Clinical characteristics and outcomes were compared between the groups; an infant group was separately analyzed (onset age younger than 3 months).

Results: Extended-spectrum $\beta$-lactamase urinary tract infection occurred in $11 \%$ patients who had more frequent previous hospitalization $(P=0.02)$ and higher recurrence rate $(P=0.045)$. During the antimicrobial susceptibility test, the extendedspectrum $\beta$-lactamase-positive urinary tract infection group showed resistance to third-generation cephalosporins; however, $98 \%$ patients responded clinically. In the infant group, extended-spectrum $\beta$-lactamase-positive urinary tract infection occurred in $13 \%$ patients and was associated with a longer pre-onset hospitalization history $(P=0.002)$, higher $C$-reactive protein level $(P=0.04)$, and higher recurrence rate $(P=0.02)$ than that in the older group.

Conclusion: Extended-spectrum $\beta$-lactamase urinary tract infection requires more attention because of its higher recurrence rate. The antimicrobial susceptibility test demonstrated resistance to third-generation cephalosporins, but they can be used as first-line empirical antibiotics because of their high clinical response rate. Aminoglycosides can be second-line antibiotics before starting carbapenems when third-generation cephalosporins do not show bactericidal effects for extended-spectrum $\beta$-lactamase urinary tract infection.

Key words: Extended-spectrum $\beta$-lactamase, Urinary tract infection, Age, Cephalosporin

\section{Introduction}

Urinary tract infection (UTI) is one of the most common bacterial infections in children ${ }^{1)}$. Depending on the location of the UTI, whether the lower or upper urinary tract or renal parenchyma, the severity of its clinical 
presentation and possible acute and long-term complications are different ${ }^{2,3}$. Acute pyelonephritis (APN) may result in renal scarring, which can lead to long-term sequelae such as chronic kidney damage, hypertension, and endstage renal disease (ESRD) ${ }^{4)}$. Furthermore, inadequate treatment of febrile UTI may cause renal scarring due to APN and chronic renal damage. Therefore, proper antibiotic treatment is important for preventing such clinical consequences.

Extended-spectrum $\beta$-lactamase (ESBL)-producing bacteria are capable of degrading the $\beta$-lactam ring of most penicillins and cephalosporins ${ }^{5}$. Additionally, other genes encoding resistance to other antimicrobial agents such as aminoglycosides and fluoroquinolones are often found in proximity to the genes encoding ESBL on bacterial plasmids, thereby conferring multidrug resistance patterns ${ }^{6}$. Escherichia coli and Klebsiella species have variable antimicrobial resistance mechanisms that may include the production of $\mathrm{ESBL}^{7)}$. Antibiotics of the carbapenem family are the first choice for treating ESBL-producing bacteria; however, whether to maintain or change empirical antibiotics to carbapenem for UTI with ESBL-producing bacteria is controversial.

ESBL-producing bacteria were first detected in Western Europe in the mid-1980s $\mathrm{s}^{8)}$. The presence of ESBL-producing bacteria in pediatric UTI is constantly increasing ${ }^{7,9}$. According to Orli, the incidence of community-acquired UTI with ESBL-producing bacteria in children increased from 2 to $5.25 \%$ from 2003 to 2013 in Israel ${ }^{1}$. There is some controversy regarding outcomes of UTI with ESBL-producing bacteria. Fan et al. reported that UTI with ESBL-producing bacteria prolongs hospital stay, increases medical costs, and reduces rates of clinical and microbiological responses ${ }^{9}$. However, according to Han et al., infection with ESBL-producing bacteria is associated with no significant differences in the frequency of defervescence, bacterial eradication from the urine, acute pyelonephritis, vesicoureteral reflux, or fever duration ${ }^{10}$.

The aim of this study was to evaluate the clinical difference between ESBL-positive and ESBL-negative bacteria in febrile UTI in children younger than 5 years to evaluate risk factors for $\mathrm{ESBL}^{+} \mathrm{UTI}$ and to suggest appropriate antibiotic treatment.

\section{Materials and methods}

We retrospectively studied 288 patients who were diagnosed with their first febrile UTI when they were younger than 5 years at Severance Children's Hospital from September 2013 to December 2015. Data were collected from medical records. Patients who fulfilled the diagnostic criteria of the AAP guideline were included in this study. Patients without fever or presenting recurrent UTI were excluded. Flow diagram of 288 patients with first febrile UTI analyzed in this study is shown in Fig. 1. Patients were divided into the $\mathrm{ESBL}^{+} \mathrm{UTI}$ group and the ESBL- UTI group.

Urine specimens were obtained by transurethral bladder catheterization ( $\mathrm{n}=186)$, urine bag collection methods $(\mathrm{n}=$ $100)$, and mid-stream sampling $(\mathrm{n}=2)$ for older children. UTI was diagnosed based on the guidelines defined by the American Academy of Pediatrics: findings of pyuria or bacteriuria on urine analysis (white blood cell [WBC] count $>10-20 /$ high-power field) and a positive urine culture result showing a single colony of bacteria with more than 50,000 colony-forming units (CFU)/mL with the clean catch and mid-stream collection method or more than 100,000 CFU/ $\mathrm{mL}$ with the urine bag collection method.

The data collected by urine bag measurement could increase the possibility of contamination. However, with the 186 patients who underwent both bag analysis and bladder catheterization, we could compare the results of the urine culture. 168 of 186 (90\%) showed same urine culture results

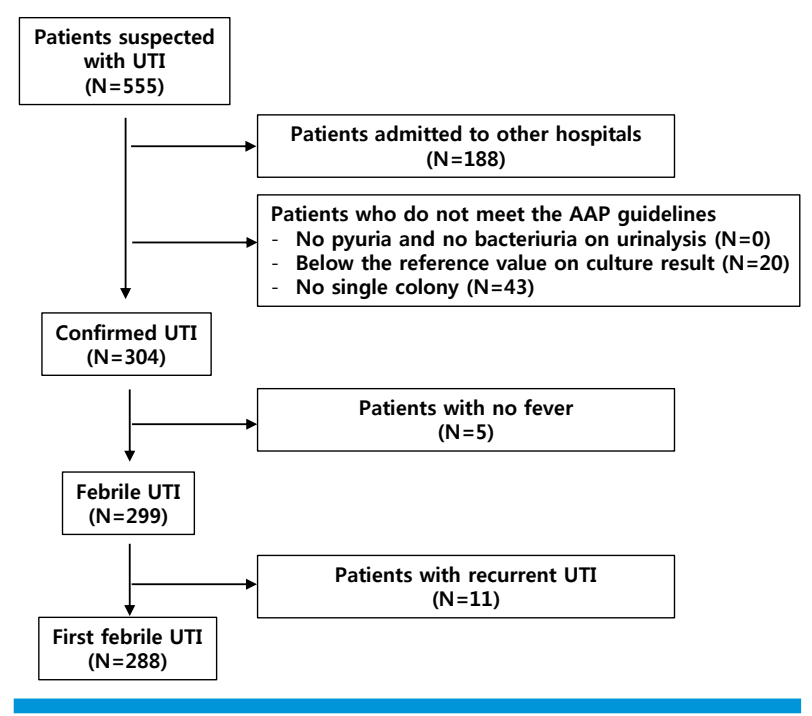

Fig.1. Flow diagram summarizing the patient selection process. 
between both specimens. 18 of 186 (10\%) bag analyses did not show the same results as bladder catheterization; however, multiple organisms were detected, which were highly indicative of urinary tract infection. Also, urine bag collection was done with similar procedures with each patient, which makes the risk of contamination unlikely to be high.

The antimicrobial susceptibility test (AST) of the isolates was performed using the standard disc diffusion method, as recommended by the Clinical and Laboratory Standards Institute. The ESBL phenotypic confirmatory test with cefotaxime was performed for all isolates by using the disc diffusion method on Mueller Hinton agar plates.

For all patients, repeated urine analyses and urine cultures were performed 18-36 hours after the first administration of empirical antibiotics. Cefotaxime, third-generation cephalosporin, was used as empirical antibiotics for all patients intravenously. The clinical effects of antibiotics were evaluated by defervescence and negative culture results after administration of antibiotics. Antibiotics has not been modified according to the antibiogram if clinical improvement with negative urine culture was observed, and intravenous therapy has been followed by oral treatment for a total of 14 days.

We compared the clinical characteristics and outcomes of the $\mathrm{ESBL}^{+} \mathrm{UTI}_{\text {group and ESBL }}{ }^{-} \mathrm{UTI}$ group to determine risk factors for $\mathrm{ESBL}^{+} \mathrm{UTI}$. Furthermore, causative organisms, AST, and antibiotic responses were analyzed in the $\mathrm{ESBL}^{+} \mathrm{UTI}$ group. Infants younger than 3 months were studied separately. This study was approved by the Institutional Review Board of Severance Hospital, Yonsei University College of Medicine, Seoul, Korea (IRB number: 42017-0347).

SPSS 20 for Microsoft Windows was used for all statistical analyses. Results for continuous variables are presented as mean \pm standard deviation and categorical variables are reported as percentages. Fisher's exact test was used to compare categorical variables. The Mann-Whitney U test was used for continuous variables. $P<0.05$ was considered statistically significant.

\section{Results}

\section{Patient characteristics}

Patients were predominantly male (73\%) and had a mean age of 6 months. Previous hospitalization was reported for $17 \%$ of all patients. The incidence of UTI with ESBL-producing bacteria was $11 \%$ (Table 1).

\section{Comparison of ESBL ${ }^{+} \mathrm{UTI}$ and ESBL- UTI}

A comparison of $\mathrm{ESBL}^{+} \mathrm{UTI}$ and ESBL $\mathrm{UTI}^{-}$groups is shown in Table 2. Patients with ESBL ${ }^{+}$UTI had a more frequent previous hospitalization $(31 \% ; P=0.02)$ than those with ESBL UTI (15\%). The mean time to defervescence after antibiotic administration was $1.14 \pm 0.90$ days (1.15 \pm 0.91 for $\mathrm{ESBL}^{+} \mathrm{UTI}$ group; $1.09 \pm 0.82$ for ESBL ${ }^{-} \mathrm{UTI}$ group; $P=0.76$ ). There were no statistically significant differences in age, sex, or incidence of hydronephrosis on antenatal sonography between the two groups. Furthermore, fever duration and hospital stay were not long for the $\mathrm{ESBL}^{+} \mathrm{UTI}$ group. No significant differences in laboratory markers representing severity of infection, such as WBC count, Creactive protein (CRP), and erythrocyte sedimentation rate (ESR), were identified. Furthermore, the results of $\beta 2$-microglobulin reflecting tubular inflammation in the early phase of UTI and image studies evaluating hydronephrosis, vesico-ureteral reflux, or renal scarring showed no significant differences between the two groups. The ESBL ${ }^{+}$UTI group had a higher recurrence rate of UTI $(34 \% ; P=0.045)$ than the ESBL- UTI group (19\%). In patients with ESBL ${ }^{+}$UTI group, 11 of 32 (34\%) patients recurred, and 8 of 11 (73\%) were same ESBL producing bacteria.

\begin{tabular}{|c|c|}
\hline Total number of patients & 288 \\
\hline Sex ratio (male/female) & 2.64 \\
\hline Age (months) & $6.0 \pm 10.0$ \\
\hline Weight (kg) & $7.5 \pm 1.8$ \\
\hline Previous hospitalization & $49(17 \%)$ \\
\hline Duration of hospitalization (days) & $4.3 \pm 1.3$ \\
\hline Sepsis* & $15(5 \%)$ \\
\hline Urine culture & $\mathrm{ESBL}^{+} 256$ (89\%), ESBL 32 (11\%) \\
\hline
\end{tabular}


Table 2. Comparison of ESBL' and ESBL ${ }^{+}$UTI Groups

\begin{tabular}{|c|c|c|c|}
\hline & $\mathrm{ESBL}^{-}(\mathrm{n}=256)$ & $\mathrm{ESBL}^{+}(n=32)$ & $P$-value \\
\hline \multicolumn{4}{|l|}{ Patient characteristics } \\
\hline Sex (male/female) & 2.77 & 1.91 & 0.35 \\
\hline Age (months) & $6.26 \pm 10.62$ & $4.31 \pm 1.94$ & 0.30 \\
\hline Previous hospitalization* & $39 / 256(15 \%)$ & 10/32 (31\%) & 0.02 \\
\hline Hydronephrosis on antenatal sonography & $6 / 256(2 \%)$ & $2 / 32(6 \%)$ & 0.22 \\
\hline Duration of hospitalization (days) & $4.27 \pm 1.14$ & $5.00 \pm 2.05$ & 0.06 \\
\hline Duration of fever (days) & $3.24 \pm 1.79$ & $3.22 \pm 1.74$ & 0.95 \\
\hline Duration of fever after antibiotics (days) & $1.15 \pm 0.91$ & $1.09 \pm 0.82$ & 0.76 \\
\hline Gastrointestinal symptom & $44 / 256(17 \%)$ & $4 / 32(12 \%)$ & 0.50 \\
\hline \multicolumn{4}{|l|}{ Laboratory findings } \\
\hline Hemoglobin (g/dL) & 14.6 & 13.2 & 0.40 \\
\hline Platelet count $\left(\times 10^{3} / \mu \mathrm{L}\right)$ & $428 \pm 110$ & $442 \pm 107$ & 0.48 \\
\hline WBC $\left(\times 10^{3} / \mu \mathrm{L}\right)$ & $15450 \pm 5790$ & $14660 \pm 5450$ & 0.47 \\
\hline MPV (fL) & $7.6 \pm 0.6$ & $7.6 \pm 0.5$ & 0.97 \\
\hline $\mathrm{ESR}(\mathrm{mm} / \mathrm{hr})$ & $33.6 \pm 24.9$ & $39.4 \pm 22.1$ & 0.23 \\
\hline $\mathrm{CRP}(\mathrm{mg} / \mathrm{L})$ & $43.5 \pm 41.4$ & $45.4 \pm 28.8$ & 0.80 \\
\hline BUN (mg/dL) & $8.2 \pm 3.2$ & $8.3 \pm 3.4$ & 0.81 \\
\hline $\mathrm{Cr}(\mathrm{mg} / \mathrm{dL})$ & $0.22 \pm 0.37$ & $0.23 \pm 0.89$ & 0.50 \\
\hline ß2-microglobulin (mg/L) & $0.69 \pm 1.87$ & $1.79 \pm 7.51$ & 0.45 \\
\hline \multicolumn{4}{|l|}{ Radiologic findings and outcomes } \\
\hline Abnormal sonographic findings & 159/256 (62\%) & 21/32 (66\%) & 0.70 \\
\hline Hydronephrosis & $36 / 159(23 \%)$ & $7 / 21(33 \%)$ & 0.30 \\
\hline DMSA abnormality & $93 / 225(41 \%)$ & $14 / 30(47 \%)$ & 0.58 \\
\hline VUR & 44/133 (33\%) & $6 / 22(27 \%)$ & 0.59 \\
\hline High-grade VUR (IV,V) & 18/44 (41\%) & $2 / 6(33 \%)$ & 0.99 \\
\hline Sepsis & $12(5 \%)$ & $3(9 \%)$ & 0.23 \\
\hline Surgery ${ }^{\dagger}$ & $6(2 \%)$ & $1(3 \%)$ & 0.57 \\
\hline Recurrence of UTI ${ }^{\ddagger}$ & $49(19 \%)$ & $11(34 \%)$ & 0.045 \\
\hline
\end{tabular}

Data are presented as mean \pm standard deviation or number (\%).

Abbreviations: WBC, white blood cell; MPV, mean platelet volume; ESR, erythrocyte sedimentation rate; CRP, C-reactive protein; BUN, blood urea nitrogen; $\mathrm{Cr}$, creatine; DMSA, dimercaptosuccinic acid; VUR, vesicoureteral reflux; UTI, urinary tract infection.

* Previous hospitalization excluded patients who were hospitalized without use of antibiotics. It indicates previous hospitalization with antibiotic treatment due to infection, and re-admission due to UTI occurred at least 2 weeks after the previous hospitalization.

${ }^{\dagger}$ Surgery included ureteroneocystostomy, deflux injection, and detrusorhaphy.

${ }^{\ddagger}$ The date of recurrence ranged from 35 to 293 days.

\section{Causative organisms of UTl and treatment response}

Causative organisms of UTI and antibiotic responses are shown in Table 3. In the ESBL- UTI group, E. coli was dominant (89\%), and Klebsiella species (4\%), Enterobacter species (3\%), Proteus mirabilis (1\%), and Citrobacter species followed. In the ESBL ${ }^{+}$UTI group, E. coli was dominant (100\%). All patients received third-generation cephalosporin parenterally. Antibiotic response was evaluated by urine culture results 18-36 hours after the first antibiotic injection. All patients infected with ESBL bacteria and 31 of 32 (97\%) $\mathrm{ESBL}^{+}$bacteria showed negative culture results after anti-
Table 3. Causative Organisms of UTI and Results of Treatment

\begin{tabular}{llrr}
\hline Organisms & \multicolumn{1}{c}{$\operatorname{ESBL}^{-}(\mathrm{n}=256)$} & $\operatorname{ESBL}^{+}(\mathrm{n}=32)$ \\
\hline & E. coli & $228(89 \%)$ & E. coli $32(100 \%)$ \\
& K. pneumoniae & $11(4 \%)$ & \\
& P. mirabilis & $3(1 \%)$ & \\
& Enterobacter spp. & $8(3 \%)$ & \\
& Citrobacter spp. & $3(1 \%)$ & \\
& Others & $3(1 \%)$ & \\
Antibiotic & \multicolumn{2}{c}{$228 / 228(100 \%)$} & $31 / 32(97 \%)^{*}$ \\
response to & & & \\
first antibiotics & & &
\end{tabular}

*One patient did not respond to third-generation cephalosporin and required carbapenem. 
biotic administration. One patient who did not respond to empirical antibiotics was treated with carbapenem and showed negative culture results. Table 4 shows the AST of patients with ESBL producing bacterial infection. All showed resistance to cefotaxime and sensitive to the carbapenem family. The aminoglycoside family, amikacin (100 $\%)$, and gentamycin (81\%) also showed high susceptibility and their mean minimal inhibitory concentration (MIC) was low.

\section{Comparison of $\mathrm{ESBL}^{+} \mathrm{UTI}$ and ESBL UTI (younger than 3 months)}

We also compared the $\mathrm{ESBL}^{+} \mathrm{UTI}$ group and ESBL ${ }^{-} \mathrm{UTI}$ group comprising patients younger than 3 months. During early infancy, the $\mathrm{ESBL}^{+} \mathrm{UTI}$ group had a more frequent previous hospitalization $(54 \% ; P=0.02)$ than the ESBL' UTI group (13\%). In addition, the $\mathrm{ESBL}^{+} \mathrm{UTI}$ group had a higher incidence of hydronephrosis on antenatal sonography (15 $\% ; P=0.015$ ) than the ESBL- UTI group (0\%) (Table 5). CRP level was increased in the $\mathrm{ESBL}^{+} \mathrm{UTI}$ group during early infancy (younger than 3 months) $(P=0.04)$. In the $\mathrm{ESBL}^{+}$ UTI group, the recurrence rate was also statistically higher $(62 \% ; P=0.02)$ than that of the ESBL UTI group (26\%).

Table 4. Antibiotic Susceptibility Test Results for ESBL Bacteria $(n=32)$

\begin{tabular}{lccc}
\hline Antibiotics & Sensitivity & Resistant & Mean MIC \\
\hline Amikacin & $32 / 32(100 \%)$ & $0 / 32(0 \%)$ & 2.38 \\
Gentamycin & $26 / 32(81 \%)$ & $6 / 32(19 \%)$ & 1 \\
Ampicillin & $0 / 32(0 \%)$ & $32 / 32(100 \%)$ & \\
Ampicillin/Sulbactam & $9 / 32(28 \%)$ & $23 / 32(72 \%)$ & 13.33 \\
Aztreonam & $15 / 32(47 \%)$ & $17 / 32(53 \%)$ & 2.07 \\
Cefazolin & $0 / 32(0 \%)$ & $32 / 32(100 \%)$ & \\
Cefoxitin & $32 / 32(100 \%)$ & $0 / 32(0 \%)$ & 7.75 \\
Cefotaxime & $0 / 32(0 \%)$ & $32 / 32(100 \%)$ & \\
Ceftazidime & $19 / 32(59 \%)$ & $13 / 32(41 \%)$ & 1.74 \\
Cefepime & $19 / 32(59 \%)$ & $13 / 32(41 \%)$ & 1.85 \\
Piperacillin/Tazobactam & $32 / 32(100 \%)$ & $0 / 32(0 \%)$ & 7.63 \\
Ertapenem & $32 / 32(100 \%)$ & $0 / 32(0 \%)$ & 0.5 \\
Meropenem & $32 / 32(100 \%)$ & $0 / 32(0 \%)$ & 0.25 \\
Levofloxacin & $15 / 32(47 \%)$ & $17 / 32(53 \%)$ & 0.64 \\
Cotrimoxazole & $20 / 32(63 \%)$ & $12 / 32(38 \%)$ & 20 \\
Tigecycline & $32 / 32(100 \%)$ & $0 / 32(0 \%)$ & 0.5 \\
\hline Abbevions: & (10) &
\end{tabular}

Abbreviations: MIC, minimal inhibitory concentration.

\section{Discussion}

ESBL-producing organisms were typically limited to healthcare facilities, but they have begun to appear in communities as well, and their prevalence is consistently increasing, as is the severity of infection ${ }^{1,9,11}$. Consequently, it is important to recognize the risk factors for ESBL-producing organisms.

There have been different results regarding severity, prognostic factors, and treatment of ESBL ${ }^{+}$UTI for children ${ }^{1,9,10 \text {, }}$ ${ }^{12)}$. Fan et al. suggested that UTI with EBSL-producing bacteria prolonged hospital stay, increased medical costs, and reduced rates of clinical and microbiologic responses ${ }^{9)}$. Dotis et al. demonstrated that children with $\mathrm{ESBL}^{+} \mathrm{UTI}$ had abnormal findings on $99 \mathrm{mTc}$ dimercaptosuccinic acid (DMSA) scans more often and had longer hospitalization periods than those with ESBL- $\mathrm{UTI}^{12)}$. Orli demonstrated that $\mathrm{ESBL}^{+} \mathrm{UTI}$ was associated with a higher rate of abnormal results on voiding cystourethrogram (VCUG) ${ }^{1)}$. However, Han et al. stated that there were no significant differences in the frequency of defervescence, bacterial eradication from the urine, acute pyelonephritis, and vesicoureteral reflux between the ESBL group and non-ESBL $\operatorname{group}^{10)}$.

In our study, the ESBL ${ }^{+}$UTI group did not show differences in clinical microbiologic response rate, renal scarring on DMSA scan, or vesicoureteral reflux on VCUG compared to ESBL' UTI group. However, our study demonstrated that $\mathrm{ESBL}^{+} \mathrm{UTI}$ was associated with a significantly higher recurrence rate of UTI. Children with $\mathrm{ESBL}^{+}$ UTI require more attention during follow-up because of UTI recurrence. Also, further study is needed if patients with $\mathrm{ESBL}^{+} \mathrm{UTI}$ are likely to repeatedly encounter the same $\mathrm{ESBL}^{+}$bacteria, because $73 \%$ of recurred patients in $\mathrm{ESBL}^{+} \mathrm{UTI}$ group infected with the same $\mathrm{ESBL}^{+}$bacteria.

Studies have indicated that previous antibiotic usage is a risk factor for $\mathrm{ESBL}^{+} \mathrm{UTI}^{1,7)}$. Kizilca et al. stated that long duration of prophylactic antibiotic usage is a significant risk factor for infection with ESBL-producing bacteria ${ }^{13}$. Our study also showed that previous hospitalization and administration of antibiotics increased the incidence of $\mathrm{ESBL}^{+}$UTI. Therefore, antibiotics administered for UTI prophylaxis can be a risk factor for ESBL bacterial infection. In our study, the influence of ESBL on UTI in infants 
Table 5. Comparison between ESBL- and ESBL+ UTI Groups (Age <3 Months)

\begin{tabular}{|c|c|c|c|}
\hline & $\mathrm{ESBL}^{-}(n=88)$ & $\operatorname{ESBL}^{+}(n=13)$ & $P$-value \\
\hline \multicolumn{4}{|l|}{ Patient characteristics } \\
\hline Sex (male/female) & 3.89 & 3.33 & 0.73 \\
\hline Admission history & $11 / 88(13 \%)$ & $7 / 13(54 \%)$ & 0.002 \\
\hline Hydronephrosis on antenatal sonography & 0/88 (0\%) & $2 / 13(15 \%)$ & 0.015 \\
\hline Duration of hospitalization (days) & $4.32 \pm 1.15$ & $5.62 \pm 2.96$ & 0.14 \\
\hline Duration of fever (days) & $2.70 \pm 1.35$ & $3.23 \pm 1.96$ & 0.22 \\
\hline Duration of fever after antibiotics (days) & $1.07 \pm 0.90$ & $1.15 \pm 1.14$ & 0.76 \\
\hline Gastrointestinal symptom & $14 / 88(16 \%)$ & $0 / 13(0 \%)$ & 0.21 \\
\hline \multicolumn{4}{|l|}{ Laboratory findings } \\
\hline Hemoglobin (g/dL) & 10.5 & 10.2 & 0.24 \\
\hline Platelet count $\left(\times 10^{3} / \mu \mathrm{L}\right)$ & $452 \pm 117$ & $443 \pm 124$ & 0.79 \\
\hline WBC $\left(\times 10^{3} / \mu \mathrm{L}\right)$ & $13,720 \pm 4560$ & $13440 \pm 4750$ & 0.84 \\
\hline MPV (fL) & $7.8 \pm 0.7$ & $7.8 \pm 0.6$ & 0.99 \\
\hline ESR (mm/hr) & $27.6 \pm 20.6$ & $38.6 \pm 22.9$ & 0.08 \\
\hline CRP (mg/L) & $32.3 \pm 26.4$ & $48.6 \pm 29.8$ & 0.04 \\
\hline BUN (mg/dL) & $8.4 \pm 2.7$ & $8.6 \pm 4.0$ & 0.89 \\
\hline $\mathrm{Cr}(\mathrm{mg} / \mathrm{dL})$ & $0.22 \pm 0.03$ & $0.25 \pm 0.13$ & 0.38 \\
\hline B2-microglobulin (mg/L) & $0.71 \pm 1.67$ & $4.34 \pm 12.55$ & 0.39 \\
\hline \multicolumn{4}{|l|}{ Radiologic findings and outcomes } \\
\hline Abnormal sonographic findings & $61 / 88(69 \%)$ & $8 / 13(62 \%)$ & 0.54 \\
\hline Hydronephrosis & $12 / 61(20 \%)$ & $3 / 8(38 \%)$ & 0.36 \\
\hline DMSA abnormality & $26 / 74(35 \%)$ & $5 / 12(42 \%)$ & 0.75 \\
\hline VUR & $13 / 45(29 \%)$ & 4/10 (40\%) & 0.48 \\
\hline High-grade VUR (IV, V) & 3/13 (39\%) & $2 / 4(50 \%)$ & 0.99 \\
\hline Sepsis & $7 / 88(8 \%)$ & $3 / 13(23 \%)$ & 0.12 \\
\hline Surgery & $4 / 88(2 \%)$ & $1 / 13(8 \%)$ & 0.50 \\
\hline Recurrence of UTI* & $23 / 88(26 \%)$ & $8 / 13(62 \%)$ & 0.02 \\
\hline
\end{tabular}

Data are presented as mean \pm standard deviation or number (\%).

Abbreviations: WBC, white blood cell; MPV, mean platelet volume; ESR, erythrocyte sedimentation rate; CRP, C-reactive protein; BUN, blood urea nitrogen; $\mathrm{Cr}$, creatine; DMSA, dimercaptosuccinic acid; VUR, vesicoureteral reflux; UTI, urinary tract infection.

*The date of recurrence ranged from 35 to 247 days.

(younger than 3 months) was analyzed separately. Infants younger than 3 months might have weaker immune systems than older children and might show different clinical features in $\mathrm{ESBL}^{+} \mathrm{UTI}$. Even though the analysis regarding CRP showed meaningful differences in the infant group with age younger than 3 months $(P=0.04)$, further study with a larger number of patients is needed to confirm whether in-depth management of $\mathrm{ESBL}^{+} \mathrm{UTI}$ is necessary in this population.

ESBL-producing bacteria were infrequent pathogens of UTI in children, but their prevalence is consistently increasing ${ }^{7,9)}$. At present, the most common options for UTI empirical therapy for children are third-generation cephalosporins ${ }^{4,14)}$. ESBL-producing bacteria are generally resistant to third-generation cephalosporin in vitro ${ }^{15)}$. However, the clinical response of ESBL-producing bacteria to antibiotics seems to be much better than their in vitro susceptibility $16,17)$.

In our study, 31 of 32 (97\%) patients with ESBL-producing bacterial infection responded to third-generation cephalosporin. Therefore, patients who responded to treatment were maintained with the same antibiotics for 14 days. This indicated that the in vitro resistance of ESBL-producing bacteria to third-generation cephalosporin documented by standard methods was not sufficiently predictive of their in vivo sensitivity. The reason for the discrepancy between in vitro and in vivo sensitivity is not yet clear. According to Vinks, the antibiotic response is affected by several fac- 
tors such as bacterial resistance mutation, patient immune function, and drug exposure ${ }^{18)}$. Gentry et al. showed most cephalosporins are excreted primarily by the kidney, and urinary concentrations routinely exceed $1,000 \mathrm{mg} / \mathrm{L}$ after even a small dose ${ }^{19)}$. This means that in urine, the antibiotics are more highly concentrated; however, the susceptibility test is mostly based on the blood concentration determination ${ }^{4}$. Therefore, we can conclude that third-generation cephalosporin can be effective for ESBL-producing bacteria in UTI, and we can keep using it if the clinical symptoms are improving.

Generally, carbapenems are recommended for treating infections with ESBL-producing strains ${ }^{20,21)}$. However, with the widespread use of carbapenems, the emergence of resistance is a matter of concern and they should be restricted ${ }^{22,}$ ${ }^{23)}$. In our study, aminoglycoside antibiotics could be the alternative to carbapenem because they showed high susceptibility and their mean MIC was low. Amikacin was particularly sensitive to ESBL-producing bacteria according to our data.

According to Table 4, 19 of 32 (59\%) ESBL isolates were sensitive to ceftazidime and cefepime, and 32 of 32 (100\%) to cefoxitin. In our hospital, ESBL phenotypic confirmatory test was done with cefotaxime by using the disc diffusion method. Sensitivity and treatment response to cefoxitin, ceftazidime, cefotaxime and cefepime in ESBL can vary with subtypes of ESBL ${ }^{+}$bacteria. For example, CTX-M beta-lactamase, which is one variety of ESBLs, has greater resistance to cefotaxime than others such as ceftazidime, ceftriaxone, and cefepime ${ }^{24)}$. Also, favorable response to treatment with cefotaxime than ceftazidime was observed for TEM- 6 and TEM-12, as their ESBLs have relatively weaker hydrolytic activity against extended-spectrum cephalosporins ${ }^{25}$. Subtypes of ESBL are not identified in our study because of its retrospective nature. However, identifying dominant subtypes of ESBL can be helpful in determining appropriate antibiotics, and further study is needed about this.

Our study has several limitations. Data analyses were performed retrospectively using patient medical records. Also, the urine culture method included urine bag measurement, which could increase the possibility of contamination. In the future, a prospective, large-scale, longitudinal study is necessary to investigate clinical characteristics of
$\mathrm{ESBL}^{+} \mathrm{UTI}$ according to patient age, disease course, and treatment response. Results from such a study might lead to an appropriate therapeutic guideline for the clinical management of $\mathrm{ESBL}^{+} \mathrm{UTI}$.

In conclusion, $\mathrm{ESBL}^{+} \mathrm{UTI}$ requires more attention because of its high recurrence rate. Infants younger than 3 months with a previous hospitalization had more severe infections and higher recurrence rates; therefore, we should select antibiotics carefully. Third-generation cephalosporins showed resistance in the AST, but can be used as firstline empirical antibiotics because of their high clinical response rate. For ESBL ${ }^{+}$UTI resistant to third-generation cephalosporin, we can also consider aminoglycoside as a second-line antibiotic before starting carbapenem.

\section{Conflicts of interest}

No potential conflict of interest relevant to this article was reported.

\section{References}

1. Megged O. Extended-spectrum beta-lactamase-producing bacteria causing community-acquired urinary tract infections in children. Pediatr Nephrol 2014;29:1583-7.

2. Roberts KB. A synopsis of the American Academy of Pediatrics' practice parameter on the diagnosis, treatment, and evaluation of the initial urinary tract infection in febrile infants and young children. Pediatr Rev 1999;20:344-7.

3. Doganis D, Siafas K, Mavrikou M, Issaris G, Martirosova A, Perperidis $G$, et al. Does early treatment of urinary tract infection prevent renal damage? Pediatrics 2007;120:e922-8.

4. Peco-Antic A, Paripovic D, Buljugic S, Spasojevic-Dimitrijeva B, Cvetkovic M, Laban-Nestorovic S, et al. In vivo susceptibility of ESBL producing Escherichia coli to ceftriaxone in children with acute pyelonephritis. Srp Arh Celok Lek 2012;140:321-5.

5. Oteo J, Perez-Vazquez M, Campos J. Extended-spectrum [beta]lactamase producing Escherichia coli: changing epidemiology and clinical impact. Curr Opin Infect Dis 2010;23:320-6.

6. Lautenbach E, Strom BL, Bilker WB, Patel JB, Edelstein PH, Fishman NO. Epidemiological investigation of fluoroquinolone resistance in infections due to extended-spectrum beta-lactamase-producing Escherichia coli and Klebsiella pneumoniae. Clin Infect Dis 2001;33:1288-94.

7. Dayan N, Dabbah H, Weissman I, Aga I, Even L, Glikman D. Urinary 


\section{www.chikd.org}

tract infections caused by community-acquired extended-spectrum beta-lactamase-producing and nonproducing bacteria: a comparative study. J Pediatr 2013;163:1417-21.

8. Shaikh S, Fatima J, Shakil S, Rizvi SM, Kamal MA. Antibiotic resistance and extended spectrum beta-lactamases: Types, epidemiology and treatment. Saudi J Biol Sci 2015;22:90-101.

9. Fan NC, Chen HH, Chen CL, Ou LS, Lin TY, Tsai MH, et al. Rise of community-onset urinary tract infection caused by extendedspectrum beta-lactamase-producing Escherichia coli in children. J Microbiol Immunol Infect 2014;47:399-405.

10. Han SB, Lee SC, Lee SY, Jeong DC, Kang JH. Aminoglycoside therapy for childhood urinary tract infection due to extendedspectrum beta-lactamase-producing Escherichia coli or Klebsiella pneumoniae. BMC Infect Dis 2015;15:414.

11. Cheng MF, Chen WL, Huang IF, Chen JR, Chiou YH, Chen YS, et al. Urinary tract infection in infants caused by extended-spectrum beta-lactamase-producing Escherichia coli: comparison between urban and rural hospitals. Pediatr Nephrol 2016;31:1305-12.

12. Dotis J, Printza N, Marneri A, Gidaris D, Papachristou F. Urinary tract infections caused by extended-spectrum betalactamaseproducing bacteria in children: a matched casecontrol study. Turk J Pediatr 2013;55:571-4.

13. Kizilca O, Siraneci R, Yilmaz A, Hatipoglu N, Ozturk E, Kiyak A, et al. Risk factors for community-acquired urinary tract infection caused by ESBL-producing bacteria in children. Pediatr Int 2012; 54:858-62.

14. Stein R, Dogan HS, Hoebeke P, Kocvara R, Nijman RJ, Radmayr C, et al. Urinary tract infections in children: EAU/ESPU guidelines. Eur Urol 2015;67:546-58.

15. Rodriguez-Bano J, Navarro MD, Romero L, Martinez-Martinez L, Muniain MA, Perea EJ, et al. Epidemiology and clinical features of infections caused by extended-spectrum beta-lactamase-producing Escherichia coli in nonhospitalized patients. J Clin Microbiol 2004;42:1089-94.
Park SY and Kim JH • Clinical Significance of ESBL-UTI in Children 135

16. Du B, Long Y, Liu H, Chen D, Liu D, Xu Y, et al. Extended-spectrum beta-lactamase-producing Escherichia coli and Klebsiella pneumoniae bloodstream infection: risk factors and clinical outcome. Intensive Care Med 2002;28:1718-23.

17. Ramphal R, Ambrose PG. Extended-spectrum beta-lactamases and clinical outcomes: current data. Clin Infect Dis 2006;42 Suppl 4:S164-72.

18. Vinks AA, Derendorf H, Mouton JW. Fundamentals of antimicrobial pharmacokinetics and pharmacodynamics. Springer, New York, 2014;137-146

19. Gentry LO. Cephalosporins in urinary tract infection. Drugs 1987; 34 Suppl 2:154-63.

20. Pitout JD, Laupland KB. Extended-spectrum beta-lactamaseproducing Enterobacteriaceae: an emerging public-health concern. Lancet Infect Dis 2008;8:159-66.

21. Rupp ME, Fey PD. Extended spectrum beta-lactamase (ESBL)producing Enterobacteriaceae: considerations for diagnosis, prevention and drug treatment. Drugs 2003;63:353-65.

22. Rahal JJ, Urban C, Horn D, Freeman K, Segal-Maurer S, Maurer J, et al. Class restriction of cephalosporin use to control total cephalosporin resistance in nosocomial Klebsiella. Jama 1998;280:12337.

23. Lee SO, Kim NJ, Choi SH, Hyong Kim T, Chung JW, Woo JH, et al. Risk factors for acquisition of imipenem-resistant Acinetobacter baumannii: a case-control study. Antimicrob Agents Chemother 2004;48:224-8.

24. Lahlaoui H, Ben Haj Khalifa A, Ben Moussa M. Epidemiology of Enterobacteriaceae producing CTX-M type extended spectrum beta-lactamase (ESBL). Med Mal Infect 2014;44:400-4.

25. Wong-Beringer A, Hindler J, Loeloff M, Queenan AM, Lee N, Pegues DA, et al. Molecular correlation for the treatment outcomes in bloodstream infections caused by Escherichia coli and Klebsiella pneumoniae with reduced susceptibility to ceftazidime. Clin Infect Dis 2002;34:135-46. 